\title{
Bayesian networks for unbiased assessment of referee bias in Association Football
}

\author{
Anthony Costa Constantinou ${ }^{* 1,2}$, Norman Elliott Fenton' ${ }^{1}$, Liam Jackson Hunter Pollock ${ }^{3}$ \\ 1. Risk and Information Management Research Group, School of Electronic Engineering \\ and Computer Science. \\ 2. Forensic Mental Health Research Group, Centre for Psychiatry, Wolfson Institute of \\ Preventive Medicine, Barts and The London School of Medicine and Dentistry. \\ 3. Biological and Experimental Psychology Research Group, The School of Biological and \\ Chemical Sciences.
}

Queen Mary, University of London, London, UK, E1 4NS

* Corresponding author. E-mail address: anthony@constantinou.info

\section{ABSTRACT}

We present a novel Bayesian network model for assessing referee bias with respect to fouls and penalty kicks awarded. Unlike previous studies, our model takes into consideration explanatory factors which, if ignored, can lead to biased assessments of referee bias. For example, a team may be awarded more penalties simply because it attacks more, not because referees are biased in its favour. Hence, we incorporate causal factors such as possession, time spent in the opposition penalty box, etc. prior to estimating the degree of penalty kicks bias. The model is applied to the 2011-12 English Premier League season. Among our conclusions are that, in contrast to previous studies, being the home team does not in itself result in positive referee bias. Conversely Arsenal, a team of similar popularity and wealth and who finished third, benefited least of all 20 teams from referee bias at home with respect to penalty kicks awarded.

Keywords: causal modelling, crowd effect, home advantage, officiating bias, soccer

The notion that referees in Association Football (hereafter referred to simply as football) are biased towards certain teams or in certain contexts is widely accepted by football pundits and supporters. In fact, whether or not such bias exists is an area of increasing interest that attracts the attention of researchers from the domains of sport science, psychology, statistics and computer science.

Irrespective of the true underlying causes, there is no doubt that 'playing at home' has a significant impact on a team's success. This home advantage effect has been extensively studied (Courneya \& Carron, 1992; Nevill \& Holder, 1999; Hirotsu \& Wright, 2003; Pollard \& Pollard, 2005; Pollard, 1986; 2006; Poulter, 2009; Anders \& Rotthoff, 2012; Constantinou 
\& Fenton, 2013). Numerous explanatory factors have been proposed for home advantage. The crowd effect is normally suggested as one of the most important factors (Agnew \& Carron, 1994; Nevill et al., 1996; Nevill et al., 1999; 2002; Downward \& Jones, 2007; Dohmen, 2008; Goumas, 2012) and is said to occur to a greater extent in leagues in which home crowds are more hostile and vociferous (Anders \& Rotthoff, 2012). Other proposed factors include the travelling effect (Clarke \& Norman, 1995), the familiarity with the playing grounds (Neave \& Wolfson, 2003; Pollard, 2006), as well as referees themselves who are said to favour home teams on the basis of penalty kicks, free kicks, yellow/red cards and/or extra time data (Nevill et al., 1996; Nevill et al., 1999; 2002; Sutter \& Kocher, 2004; Boyko et al., 2007; Downward \& Jones, 2007; Dawson et al., 2007; Dohmen, 2008; Buraimo et al., 2010; Goumas, 2012). However, the degree of influence of referee decisions relative to the overall home advantage effect has not been extensively studied.

It is apparent that the literature tends to indicate with strong belief that referee decisions favour the home team. However, some researchers (Page \& Page, 2010) have questioned this outcome and expressed their uncertainty as "it could be the case that these biases do not manifest themselves into significant differences in terms of the overall performance of a team" (Page \& Page, 2010); the increased number of fouls, yellow cards, red cards, penalties and so on in favour of the home team might simply be the result of the home team performing better than the away team. For example, if the home team is in control of the ball (possession) more often than not, then we would expect it to be awarded more fouls and penalties, and less yellow and red cards relative to the opponent, on the basis that its control of possession will lead to it being on the receiving end of more tackles. We should also expect a higher proportion of these to be committed nearer to the opponent's goal, as greater possession also tends to correspond to a marked territorial advantage. We agree that the kind of explanatory causal factors proposed in (Page \& Page, 2010) must be incorporated into any study of referee bias.

Hence, in this paper we present a novel Bayesian network $(\mathrm{BN})$ model developed for referee bias analysis in football. It is the most comprehensive attempt to date to include within-game explanatory variables in order to justify the observed discrepancies between fouls and penalty kicks awarded between adversaries prior to formulating beliefs about referee bias. Although previous attempts have been made to control within-game events such as shots, fouls and corners (Dohmen, 2008; Goumas, 2012), this paper integrates a number of important additional variables which are required for formulating a causal network model, . 
70 The paper is organised as follows: Section 2 describes the BN model, Section 3 discusses the 71 results and Section 4 provides our concluding remarks.

72

73

74

2 THE MODEL

75

76 In this section we describe the BN model which was developed using the AgenaRisk BN tool

77 (Agena Ltd., 2013). Details about the role of qualitative judgments and how inference is 78 done are provided in (Fenton et al., 2007; Neil et al., 2010; Fenton \& Neil, 2012).

79 


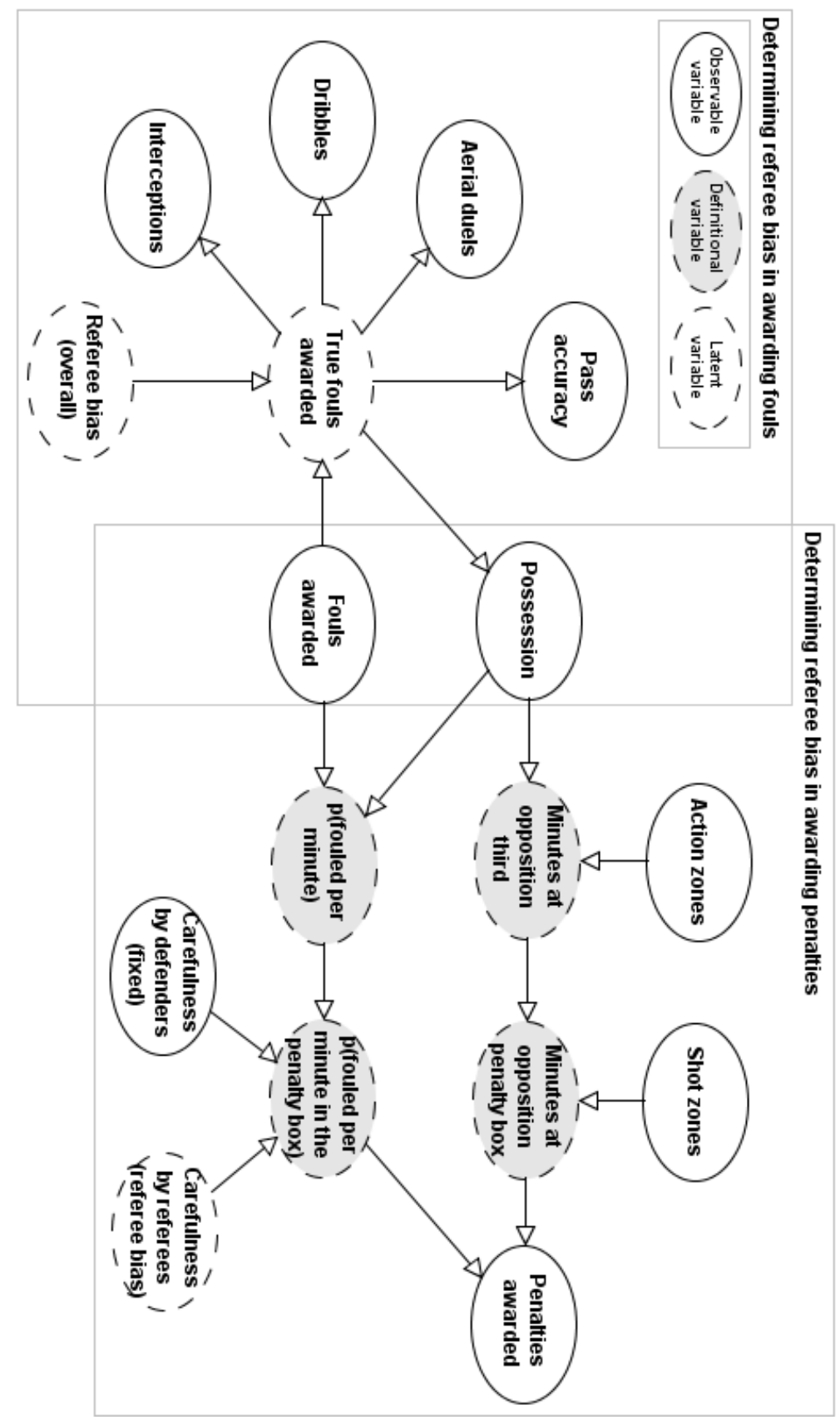

Figure 1. Bayesian network model topology; Components 1 and 2.

The data used to inform priors and provide observations for each of the teams is available online at (WhoScored?.com, 2012), although the data for number of penalties awarded was manually recorded by a member of the research team from bbc.co.uk/football.

The model is constructed on the basis of two components as illustrated by the model topology in Figure 1. Component 1 (described in Section 2.1) measures the referee bias over all fouls awarded, while Component 2 (described in Section 2.2) measures the referee bias over fouls awarded within the opposition penalty box (effectively penalty kicks). .

The model is used to assess the referee bias for each case at home, away, and overall. 

6

\subsection{COMPONENT 1}

This component simply assumes that the fouls awarded in a game are a consequence of a team's ability with respect to the following attributes (each corresponding to a node in the model):

1. Possession: percentage of time the team is in control of the ball ;

2. Pass accuracy: the percentage of successful passes (i.e. those that reach a team mate, ;

3. Aerial duels: the percentage of aerial duels won ;

4. Dribbles: the average number of times, per match instance, a player manoeuvres the ball around a player of the opposing team ;

5. Interceptions: the average number of times, per match instance, a player intercepts a pass made by a player of the opposing team .

Subsequently, the referee bias is simply inferred by measuring the discrepancy ${ }^{1}$ in distributions between predicted (True fouls awarded node) and observed (Fouls awarded node) fouls awarded, with the bias level set to $\geq 10 \%$ in terms of variability between the two distributions.

Figure A.1 presents a BN example of this component with the observations of QPR and Arsenal as inputs when playing at away grounds. The comparison in Figure A.1 shows that even though Arsenal generated superior statistics for all of the five explanatory parameters, they were still awarded 1.1 fouls less per match instance compared to QPR. As a result, the Referee bias distribution provides weak evidence of Bias For for QPR and Bias Against for Arsenal.

(1)

\subsection{COMPONENT 2}


The second component represents the key process of determining referee bias given penalties awarded. The steps can be enumerated as follows:

1. We convert the possession rate into time spent (in minutes) holding the ball, and we use the positional statistics of Action Zones ${ }^{2}$ and Shot Zones ${ }^{3}$ to estimate the time spent respectively at a) opposition third, and subsequently at b) opposition penalty box. Essentially, we are only interested in (b), since there is where the penalties are awarded.

2. We then measure the probability of being awarded a foul for each minute spent while in possession of the ball, at any part of the pitch, given the following two parameters: a) the rate of observed fouls awarded from Component 1, and b) time spent holding the ball (from step 1 above).

Similar to step 2, we measure the probability of being awarded a foul for each minute spent while in possession of the ball in the opposition penalty box given the following two parameters: a) number of penalties awarded, and b) time spent holding the ball while in the opposition penalty box (from step $1 \mathrm{~b}$ above). For the analysis we assume that fouls awarded within the penalty box are penalty kicks (there are examples of indirect free kicks in the penalty area but these are rare).

After steps 2 and 3, we can compare the two inferred probability distributions and measure how the probability of fouls awarded per minute varies with fouls awarded per minute while in opposition penalty box. In doing so, the model takes account of the extra sensitivity of fouls committed inside the penalty area since a penalty kick awarded is very often decisive ${ }^{5}$ on the final outcome. As a result, for this analysis we take into consideration the following widely accepted observations that a) when a player is defending in his own penalty box he is

\footnotetext{
${ }^{2}$ The positional statistical information regarding action zones (i.e. where the ball is played) is distributed in $O w n$ Third, Middle and Opposition Third. This information is used to estimate the time spent at each third of the pitch, while in possession of the ball.

${ }^{3}$ The positional statistical information regarding shot zones (i.e. where do the shots come from) is distributed in 6 Yards Box, 18 Yards Box, and Outside of Box. This information is used to estimate time spent at opposition penalty box while in possession of the ball (both the 6 Yards Box and the 18 Yards Box information contribute to time spent at opposition penalty box).

${ }^{5}$ In particular, during our period of analysis, $72 \%$ of penalties awarded were converted by the attacking team, while a single goal would have been sufficient to decisively alter the balance of the overall result in $61 \%$ of matches played.
} 


9

extra careful not to commit a foul, and b) the referee is also extra careful when awarding such fouls. Accordingly, the next step is:

4. To let the model explain the discrepancies between the two inferred probability distributions (from steps 2 and 3) into the following two explanatory variables: 1) Carefulness by defenders, and 2) Carefulness by referees. Since we are only interested in inferring the referee bias, we assume that the level of carefulness by defenders is fixed and identical for all teams (the assumption we use is 'double careful'). The model then explains the residual variation in node Carefulness by referees; effectively referee bias (i.e. the less careful referees are the more penalties a team is awarded and thus, the higher the positive referee bias). In particular, we assume that if referees are more (respectively less) likely - all factors being equal - to award penalties to a particular team than to the other teams, then there is a degree of positive (respectively negative) bias towards that team.

\section{RESULTS AND DISCUSSION}

Using data from the full English Premier League (EPL) season 2011-12, we have compared a) the referee carefulness given fouls awarded between teams (Component 1), b) the referee carefulness given penalties awarded between teams (Component 2), and c) the association of (a) and (b) inferences with crowd attendance and crowd density for each team.

Table C.1. presents the relative percentage increase in performance, for each of the explanatory variables, a team gained when playing at home relative to the away match performances. As expected, the average team demonstrated increases in possession (5.94\%), pass accuracy (0.94\%), aerial duels won (4.57\%), successful dribbles (13.24\%) and fouls awarded $(3.04 \%)$. When it comes to interception, the average team demonstrated a decrease of $1.34 \%$, although this is not surprising since in order to be able to intercept the ball the opponent has to be in possession. However, the variability between teams for this particular factor is very high. $\cdot$ 

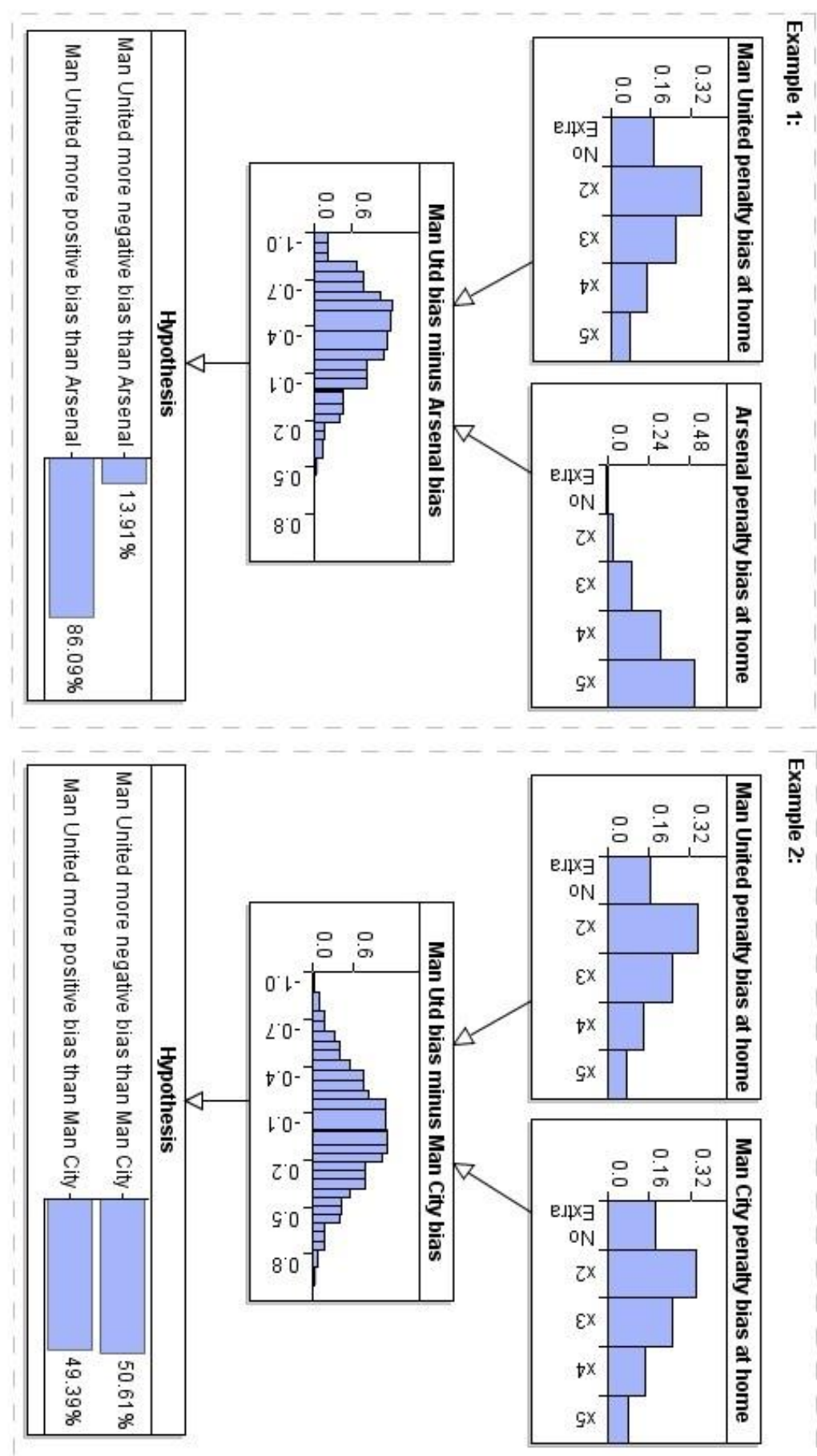
191

\subsection{Referee bias given penalties awarded (Component 2)}

Conversely, neither of the teams appear to have received similar benefit when playing away from home. But, what makes this result particularly interesting is that these two teams were the only teams fighting for the EPL title and until the very last league match (i.e. each accumulated 89 league points; an impressive 19 points more than Arsenal who finished $3^{\text {rd }}$ ). Taking into consideration both home and away match instances, however, Manchester United is still ranked $1^{\text {st }}$ in positive penalty kicks bias whereas Manchester City $4^{\text {th }}$ and Arsenal last.

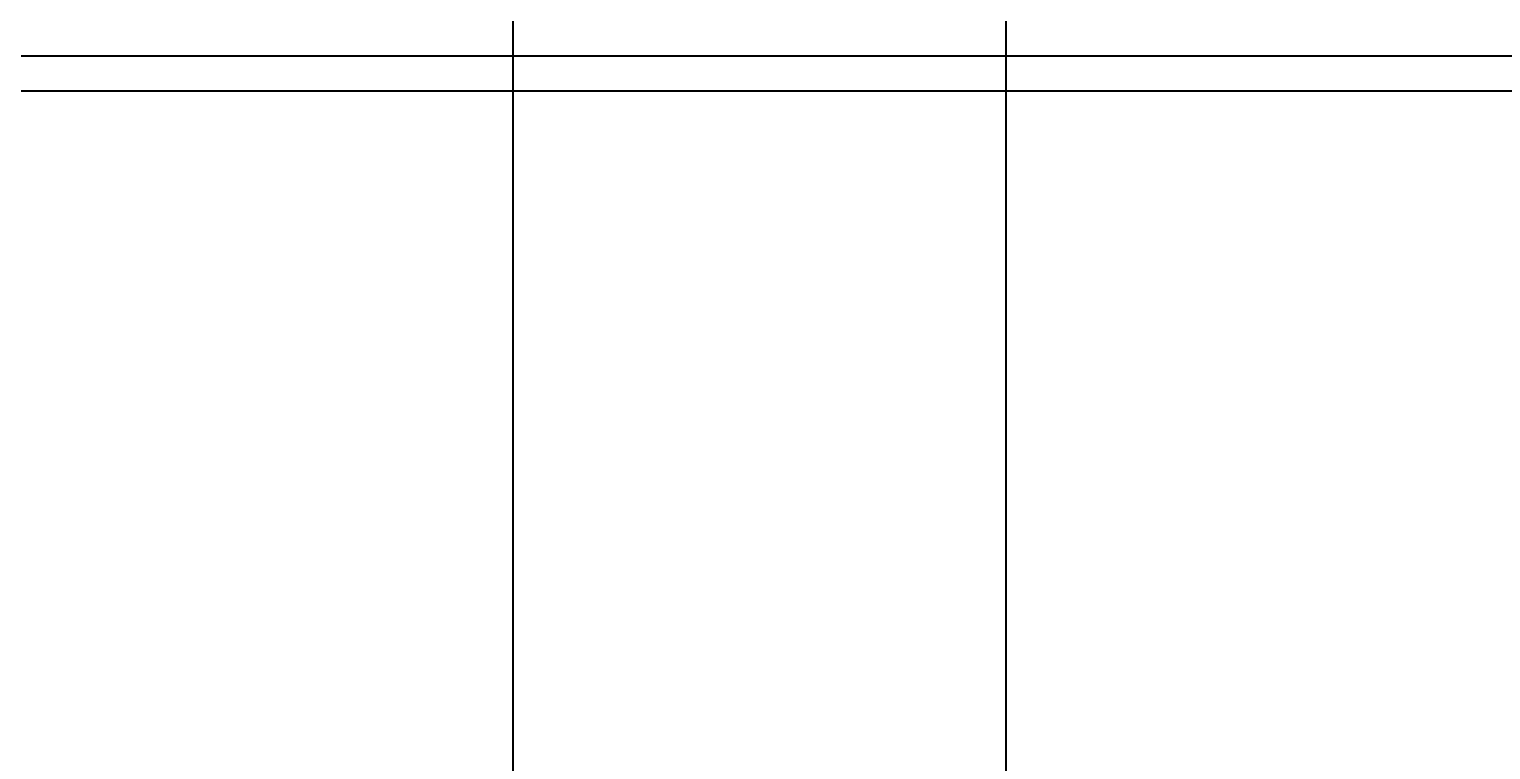

\subsection{Referee bias and match attendance}


206 with their respective average crowd attendance and average crowd density. Crowd density is 207 the attendance size divided by home stadium attendance. It has been suggested in the literature as a significant predictor of home referee bias (e.g. Boyko et al., 2007; Goumas, 2012). In contrast to previous studies, our results do not demonstrate any strong positive relationship between crowd attendance (or crowd density) and positive referee bias. For example Arsenal, with the second largest average attendance as well as the second largest average crowd density, were ranked last in terms of positive referee bias for penalties awarded.

Table 3. Average home attendance and crowd density for all teams, ranked by home $\mathrm{H}_{\mathrm{PO}}$.

\begin{tabular}{l|c|c|c} 
& Team & $\begin{array}{c}\text { Average crowd } \\
\text { attendance }\end{array}$ & $\begin{array}{c}\text { Average } \\
\text { crowd density }\end{array}$ \\
\hline & Man United & 75,387 & $99.06 \%$ \\
\hline & Man City & 47,044 & $98.01 \%$ \\
\hline & Swansea & 19,946 & $96.35 \%$ \\
\hline & Blackburn & 22,551 & $70.12 \%$ \\
\hline & Stoke & 27,225 & $95.92 \%$ \\
\hline & Fulham & 25,293 & $98.50 \%$ \\
\hline & Norwich & 26,605 & $97.74 \%$ \\
\hline & QPR & 18,923 & $94.25 \%$ \\
\hline & Chelsea & 41,477 & $99.14 \%$ \\
\hline & Liverpool & 44,253 & $97.55 \%$ \\
\hline & Bolton & 23,669 & $82.40 \%$ \\
\hline & Everton & 33,228 & $81.90 \%$ \\
\hline & Wigan & 18,633 & $74.46 \%$ \\
\hline & Aston Villa & 33,873 & $79.17 \%$ \\
\hline & Newcastle & 49,939 & $95.30 \%$ \\
\hline & West Brom & 24,773 & $93.48 \%$ \\
\hline & Wolves & 25,684 & $81.02 \%$ \\
\hline & Sunderland & 39,095 & $79.78 \%$ \\
\hline & Tottenham & 36,026 & $99.31 \%$ \\
\hline & Arsenal & 60,000 & $99.28 \%$
\end{tabular}

Any credible attempt to determine referee bias in football matches must take account of causal explanatory factors. We have presented a novel Bayesian network model for this purpose. The model enables us to account for the observed discrepancies in fouls and penalty

224 kicks awarded between teams by taking into consideration causal factors such as possession, time spent in the opposition penalty box while in control of the ball, pass accuracy, the ability 
to win aerial duels in the air, the ability to dribble the ball and the ability to intercept the opponent's pass.

However, this did not extend to away games (Manchester City, in fact benefited less than any other team away from home) nor to free kicks generally. The two Manchester clubs were, however, the only serious title contenders in an extremely close title-race. While popular lay theories suggest that referees have a tendency to favour elite clubs in general and Manchester United in particular, at their home stadiums, it is possible that the combination of home advantage and being a title-favourite team (which Manchester United have been since the Premier League inception) in a close-title race is what is more predictive of positive referee bias for penalty kicks awarded. To test such hypothesis properly would require applying the model over multiple seasons.

Other important results from applying our model to the 2011-12 EPL season run counter to the prevailing wisdom. For example, much of the previous literature suggests that the influence of home crowd is a leading factor in explaining the observed discrepancies of officiating behaviour between home and away teams (Nevill et al., 1996; Nevill et al., 1999; 2002; Downward \& Jones, 2007; Dohmen, 2008; Buraimo et al., 2010; Goumas, 2012). However, we found that the home crowd alone is not associated with positive referee bias. It should be acknowledged that there is some evidence that refereeing bias varies from league to league in conjunction with crowd hostility (Anders \& Rotthoff, 2012), and caution should therefore be exercised in generalising the findings of the present study to all of world football prior to the application of BN modelling to other major leagues. In order to formulate such a conclusion, one has not only to understand the degree of impact of home crowd on home advantage, but also to measure home advantage for individual teams before assessing referee bias. After all, crowd attendance and crowd density tend to vary in conjunction with team performance (i.e. teams which perform best tend to have a large fan base and thus larger stadiums). In (Constantinou \& Fenton, 2013) the results show how home advantage can differ considerably between teams of the EPL, whereas (Clarke \& Norman, 1995) reported that in many cases a team can even develop a negative home advantage.

It is also important to note that neither crowd size nor crowd density is necessarily correlated with crowd noise in the intuitive manner that might be expected. No published peer-reviewed study on noise-levels within the EPL stadiums exists, but 2008 and 2011 
attempts to measure their decibel levels by Sky Sports ${ }^{6}$ and fanchants.com ${ }^{7}$ suggest little or no correlation, with several clubs with smaller attendances and lower crowd densities ranking above many of the elite teams in both studies. Factors such as differing stadium acoustics, fan demographics, and the varying levels of organisation and coordination of the most vocal elements of the home support likely play a part in this. It is also important to remember that in the EPL, a league with a high ratio of visiting supporters, there is often a very substantial level of vocal support for the away team also present at almost all fixtures, thus partly confounding the notion that larger crowd generating higher noise levels necessarily means greater vocal support for the home team.

Our results lead us to conclude that Page and Page (2010) were correct to question the effect of the home crowd in the absence of team performance. It appears that the explanatory variables taken into consideration by our model (which represent different aspects of team performance) when it comes to free kicks and penalty kicks awarded between home and away teams; crowd attendance and crowd density are not related with positive referee bias.

Whether or not there are underlying factors not yet accounted for in our model (such as 'being title contenders', having 'great wealth' or even the possibility that referees secretly support these clubs), as well as the relevance of those factors with other aspects of referee bias (i.e. yellow and red card), is a matter for future research. If information such as possession and positional statistics in combination with the ability to dribble, win aerial duels and so on) also becomes available for individual match instances (rather than overall as it was in our case) then we will be able to accurately determine referee bias with much higher confidence. This will be achieved by also looking at how certain teams might have further benefited by negative referee bias for their opponents in a match between them (i.e. the possibility that the two Manchester clubs benefited not only from penalties awarded, but also from penalties not awarded - i.e. Bias Against - for their opponents when playing against them). We anticipate that our model now lays out a coherent and rational strategy for conducting such research.

\section{REFERENCES}

[1] Agena Ltd. (2013). AgenaRisk Free Version. Retrieved online December 21, 2013, from Agena: Bayesian network and simulation software for risk analysis and decision support: http://www.agenarisk.com/products/free download.shtml

\footnotetext{
${ }^{6} \mathrm{http}: / / \mathrm{www} \cdot \mathrm{bbc}$. co.uk/dna/606/A42697579 and http://www.stoke.vitalfootball.co.uk/article.asp?a=129620

${ }^{7}$ http://epltalk.com/2011/05/13/top-20-loudest-football-grounds-in-premier-league/
} 
[2] Agnew, G., \& Carron, A. (1994). Crowd effects and the home advantage. International Journal of Sport Psychology, 25(1), 53-62.

[3] Anders, A., \& Rotthoff, W. (2012). Are Home Field Advantage and Referee Bias Driven by the Fans? Evidence from Across the Ocean. Under review. Draft available at: http://ssrn.com/abstract=2026037

[4] Boyko, R., Boyko, A., \& Boyko, M. (2007). Referee bias contributes to home advantage in English premiership football. Journal of Sports Sciences, 25(11), 1185-1194.

[5] Buraimo, B., Forrest, D., \& Simmons, R. (2010). The 12th man?: refereeing bias in English and German soccer. Journal of the Royal Statistical Society, 173, Part 2: 431-449.

[6] Clarke, S. R., \& Norman, J. M. (1995). Home ground advantage of individual clubs in English soccer. The Statistician, 44, 509-521.

[7] Constantinou, A. \& Fenton, N. (2013). Determining the level of ability of football teams by dynamic ratings based on the relative discrepancies in scores between adversaries. Journal of Quantitative Analysis in Sports, 0(0): 1-14.

[8] Courneya, K., \& Carron, A. (1992). The home advantage in sport competitions: A literature review. Journal of Sport and Exercise Psychology, 14(1), 13.

[9] Dawson, P., Dobson, S., Goddard, J., \& Wilson, J. (2007). Are football referees really biased and inconsistent?: Evidence on the incidence of disciplinary sanction in the English Premier League. Journal of the Royal Statistical Society: Series A (Statistics in Society), 170(1), 231-250.

[10] Dohmen, T. J. (2008). The Influence of Social Forces: Evidence from the Behavior of Football Referees. Economic Inquiry, 46(3), 411-424.

[11] Downward, P., \& Jones, M. (2007). Effects of crowd size on referee decisions: Analysis of the FA Cup. Journal of Sports Sciences, 25(14), 1541-1545.

[12] Fenton, N. E., Neil, M. \& Caballero J. G. (2007). Using Ranked nodes to model qualitative judgements in Bayesian Networks. IEEE TKDE, 19(10), 1420-1432.

[13] Fenton, N. E. \& Neil, M. (2012). Risk Assessment and Decision Analysis with Bayesian Networks. CRC Press.

[14] Garicano, L., Palacios-Huerta, I., \& Prendergast, C. (2005). Favoritism under social pressure. Review of Economics and Statistics, 87(2), 208-216.

[15] Goumas, C. (2012). Home advantage and referee bias in European football. European Journal of Sport Science, iFirst article: $1-7$

[16] Hirotsu, N., \& Wright, M. (2003). An evaluation of characteristics of teams in association football by using a Markov process model. The Statistician, 52: 4, 591-602.

[17] Neave, N., \& Wolfson, S. (2003). Testosterone, territoriality, and the'home advantage'. Physiology and Behavior, 78(2), 269-275.

[18] Neil, M., Marquez, D. \& Fenton, N. E. (2010). Improved Reliability Modeling using Bayesian Networks and Dynamic Discretization. Reliability Engineering \& System Safety, 95(4), 412-425.

[19] Nevill, A., Balmer, N., \& Williams, A. (2002). The influence of crowd noise and experience upon refereeing decisions in football. Psychology of Sport and Exercise, 3(4), 261-272.

[20] Nevill, A., Balmer, N., \& Williams, M. (1999). Crowd influence on decisions in association football. Lancet, 353(9162), 1416.

[21] Nevill, A., \& Holder, R. (1999). Home advantage in sport: An overview of studies on the advantage of playing at home. Sports Medicine, 28(4), 221-236.

[22] Nevill, A., Newell, S., \& Gale, S. (1996). Factors associated with home advantage in English and Scottish soccer matches. Journal of Sports Sciences, 14(2), 181-186.

[23] Page, K. \& Page, L. (2010). Alone against the crowd: Individual differences in referees' ability to cope under pressure. Journal of Economic Psychology, 31: 192-199.

[24] Pollard, R. (1986). Home advantage in soccer: A retrospective analysis. Journal of Sports Sciences, 4(3), 237-248.

[25] Pollard, R. (2006). Worldwide regional variations in home advantage in association football. Journal of Sports Sciences, 24(3), 231-240.

[26] Poulter, D. R. (2009). Home advantage and player nationality in international club football. Journal of Sports Sciences, 27(8): 797-805.

[27] Pollard, R., \& Pollard, G. (2005). Long-term trends in home advantage in professional team sports in North America and England (1876-2003). Journal of Sports Sciences, 23(4), 337-350.

[28] Sutter, M., \& Kocher, M. (2004). Favoritism of agents - The case of referees' home bias. Journal of Economic Psychology, 25(4), 461-469. 
[29] WhoScored?.com (2012). WhoScored?.com: Revolutionising Football Statistics. Retrieved online

364 APPENDIX A: BN model examples with scenarios 

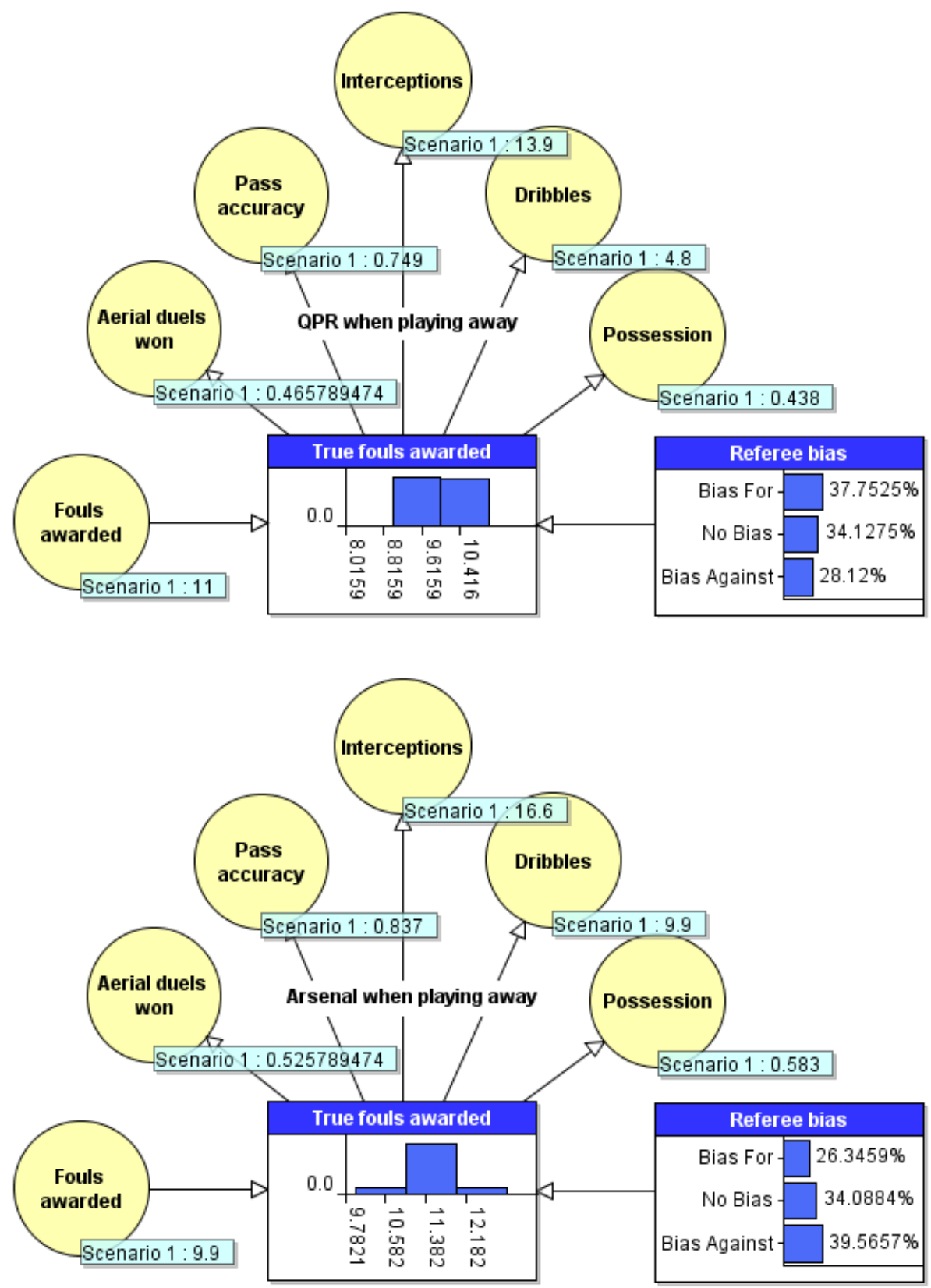

Figure A.1. Assessing referee bias given overall fouls awarded; a Component 1 example given observations of QPR and Arsenal when playing at away grounds. 


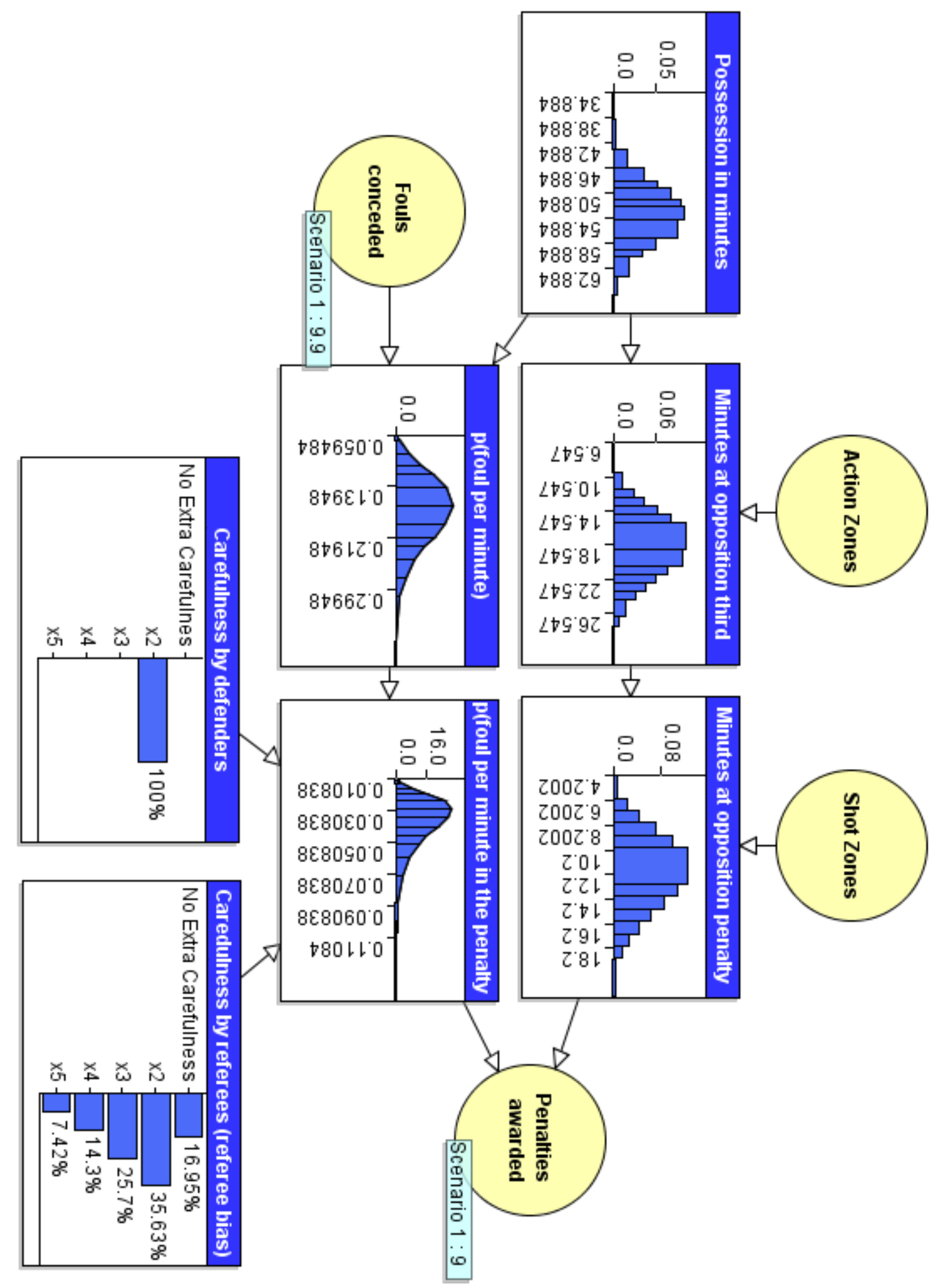

Figure A.2. Assessing referee bias given penalties awarded; a Component 2 example based on Manchester United home match data of the EPL season 2011-12. 
Table B.1. Description of the BN variable nodes

\begin{tabular}{|c|c|c|c|c|}
\hline Node name & $\begin{array}{c}\text { Node } \\
\text { ID }\end{array}$ & Node type & $\begin{array}{c}\text { Observable/ } \\
\text { Latent }\end{array}$ & Description \\
\hline Possession & POS & $\sim \operatorname{TNormal}\left(\mu, \sigma^{2}, 0,1\right)$ & Observable & where $\mu$ is the mean probability value \\
\hline Pass accuracy & PA & $\sim \operatorname{TNormal}\left(\mu, \sigma^{2}, 0,1\right)$ & Observable & observed over $n$ match instances, and \\
\hline Aerial duels & $\mathrm{AD}$ & $\sim \operatorname{TNormal}\left(\mu, \sigma^{2}, 0,1\right)$ & Observable & $\sigma^{2}$ is the variance associated with $\mu$ \\
\hline Dribbles & $\overline{\mathrm{DR}}$ & $\sim \operatorname{Pois}(\lambda)$ & Observable & \\
\hline Interceptions & INT & $\sim \operatorname{Pois}(\lambda)$ & Observable & where $\lambda$ is the expected value over $n$ \\
\hline Fouls Awarded & FA & $\sim \operatorname{Pois}(\lambda)$ & Observable & match instances \\
\hline True fouls awarded & TFA & $\sim \operatorname{Pois}(\lambda)$ & Latent & \\
\hline Referee bias (overall) & $\mathrm{RBO}$ & $\begin{array}{c}\text { Ranked } \\
\sim \operatorname{TNormal}\left(\mu, \sigma^{2}, 0,1\right)\end{array}$ & Latent & $\begin{array}{l}\text { with states 'Bias For', 'No Bias', and } \\
\text { 'Bias Against'. Assuming ignorant } \\
\text { prior (uniformly distributed) }\end{array}$ \\
\hline Action Zones & $\mathrm{AZ}$ & Labelled & Observable & $\begin{array}{c}\text { with states 'Own third', 'Middle third', } \\
\text { and 'Opposition third'. }\end{array}$ \\
\hline Shot Zones & SZ & Labelled & Observable & $\begin{array}{l}\text { with states '6 Yard Box', '18 Yard } \\
\text { Box', and 'Outside of Box'. }\end{array}$ \\
\hline $\begin{array}{l}\text { Minutes at opposition } \\
\text { third }\end{array}$ & MOT & $\sim \operatorname{Binomial}(\mathrm{n}, \mathrm{p})$ & Latent & $\mathrm{B}\left(\begin{array}{c}\mathrm{B}\left(90, \mathrm{POS}^{8}\right), \\
\mathrm{AZ}_{\text {OppositionThird }}\end{array}\right)$ \\
\hline $\begin{array}{l}\text { Minutes at opposition } \\
\text { penalty box }\end{array}$ & MOP & $\sim \operatorname{Binomial}(\mathrm{n}, \mathrm{p})$ & Latent & $\mathrm{B}\left(\begin{array}{c}\mathrm{MOT}, \\
\mathrm{SZ}_{6 \text { YardBox+18YardBox }}\end{array}\right)$ \\
\hline $\mathrm{p}$ (fouled per minute) & FM & $\sim \operatorname{Beta}(\alpha, \beta)$ & Latent & $\operatorname{Beta}\left(\begin{array}{c}F A \\
B(90, P O S)-F A\end{array}\right)$ \\
\hline $\begin{array}{l}\mathrm{p} \text { (fouled per minute in } \\
\text { the penalty box) }\end{array}$ & FMP & Arithmetic & Latent & $\frac{\mathrm{FM}}{(\mathrm{CD} \times \mathrm{CR})}$ \\
\hline Penalties awarded & PAW & $\sim \operatorname{Binomial}(\mathrm{n}, \mathrm{p})$ & Observable & $\begin{array}{l}\mathrm{B}(\mathrm{MOP} \times \mathrm{g}, \mathrm{FMP}) ; \text { where } \mathrm{g}=19 \\
\text { represents the number of gameweeks at } \\
\text { home/away grounds (and } 38 \text { for overall } \\
\text { assessment) }\end{array}$ \\
\hline $\begin{array}{l}\text { Carefulness by } \\
\text { defenders }\end{array}$ & $\mathrm{CD}$ & $\begin{array}{c}\text { Ranked } \\
\sim \operatorname{TNormal}\left(\mu, \sigma^{2}, 0,1\right)\end{array}$ & Latent & $\begin{array}{l}\text { with states 'No Extra Carefulness', } \\
\text { ' } x 2 \text { ', ' } x 3 \text { ', ' } x 4 \text { ' and ' } x 5 \text { '. Assuming } \\
\text { ignorant prior (uniformly distributed). }\end{array}$ \\
\hline $\begin{array}{l}\text { Carefulness by referees } \\
\text { (referee bias) }\end{array}$ & $\mathrm{CR}$ & $\begin{array}{c}\text { Ranked } \\
\sim \operatorname{TNormal}\left(\mu, \sigma^{2}, 0,1\right)\end{array}$ & Latent & $\begin{array}{l}\text { with states 'No Extra Carefulness', } \\
\text { ' } x 2 \text { ', ' } x 3 \text { ', ' } x 4 \text { ' and ' } x 5 \text { '. Assuming } \\
\text { ignorant prior (uniformly distributed). }\end{array}$ \\
\hline
\end{tabular}

\footnotetext{
${ }^{8}$ Translated into minutes
} 
APPENDIX C: Results

389

Table C.1. Relative percentage increase, of the value of the explanatory variables, for home match instances relative to away match instances.

\begin{tabular}{c|c|c|c|c|c|c|c}
$\begin{array}{c}\text { EPL } \\
\text { Position }\end{array}$ & Team & Possession & $\begin{array}{c}\text { Pass } \\
\text { accuracy }\end{array}$ & $\begin{array}{c}\text { Aerial } \\
\text { duels won }\end{array}$ & Dribbles & Interceptions & $\begin{array}{c}\text { Fouls } \\
\text { awarded }\end{array}$ \\
\hline 1 & Man City & $5.70 \%$ & $3.07 \%$ & $9.75 \%$ & $8.54 \%$ & $4.94 \%$ & $-25.66 \%$ \\
\hline 2 & Man United & $8.36 \%$ & $3.95 \%$ & $-5.15 \%$ & $33.78 \%$ & $-0.66 \%$ & $-4.81 \%$ \\
\hline 3 & Arsenal & $4.63 \%$ & $2.15 \%$ & $5.41 \%$ & $-3.03 \%$ & $-8.43 \%$ & $17.17 \%$ \\
\hline 4 & Tottenham & $5.47 \%$ & $3.24 \%$ & $4.73 \%$ & $5.95 \%$ & $1.60 \%$ & $-0.97 \%$ \\
\hline 5 & Newcastle & $15.67 \%$ & $3.18 \%$ & $5.93 \%$ & $21.05 \%$ & $-21.31 \%$ & $16.19 \%$ \\
\hline 6 & Chelsea & $6.72 \%$ & $2.50 \%$ & $18.09 \%$ & $30.77 \%$ & $14.74 \%$ & $6.60 \%$ \\
\hline 7 & Everton & $0.21 \%$ & $2.22 \%$ & $0.23 \%$ & $61.76 \%$ & $-0.61 \%$ & $15.31 \%$ \\
\hline 8 & Liverpool & $6.57 \%$ & $0.87 \%$ & $3.70 \%$ & $15.71 \%$ & $-2.96 \%$ & $-11.21 \%$ \\
\hline 9 & Fulham & $2.07 \%$ & $-0.97 \%$ & $7.29 \%$ & $-3.08 \%$ & $-7.39 \%$ & $-6.09 \%$ \\
\hline 10 & West Brom & $5.44 \%$ & $1.70 \%$ & $-0.81 \%$ & $3.23 \%$ & $5.63 \%$ & $18.60 \%$ \\
\hline 11 & Swansea & $6.08 \%$ & $1.06 \%$ & $6.05 \%$ & $1.25 \%$ & $-3.23 \%$ & $0.00 \%$ \\
\hline 12 & Norwich & $3.74 \%$ & $3.76 \%$ & $7.39 \%$ & $40.00 \%$ & $-10.77 \%$ & $-11.83 \%$ \\
\hline 13 & Sunderland & $5.59 \%$ & $0.81 \%$ & $-3.56 \%$ & $18.37 \%$ & $-18.52 \%$ & $12.63 \%$ \\
\hline 14 & Stoke & $7.81 \%$ & $-4.78 \%$ & $-4.12 \%$ & $2.78 \%$ & $8.62 \%$ & $-4.72 \%$ \\
\hline 15 & Wigan & $6.63 \%$ & $1.13 \%$ & $6.40 \%$ & $4.05 \%$ & $8.22 \%$ & $-10.26 \%$ \\
\hline 16 & Aston Villa & $10.41 \%$ & $2.50 \%$ & $13.51 \%$ & $-1.75 \%$ & $-9.31 \%$ & $5.43 \%$ \\
\hline 17 & QPR & $4.34 \%$ & $-1.20 \%$ & $-1.03 \%$ & $43.75 \%$ & $7.19 \%$ & $13.64 \%$ \\
\hline 18 & Bolton & $5.33 \%$ & $-1.38 \%$ & $-8.82 \%$ & $-35.14 \%$ & $-9.90 \%$ & $8.99 \%$ \\
\hline 19 & Blackburn & $6.23 \%$ & $-2.59 \%$ & $15.62 \%$ & $-12.12 \%$ & $18.50 \%$ & $14.61 \%$ \\
\hline 20 & Wolves & $1.69 \%$ & $-2.33 \%$ & $10.78 \%$ & $28.95 \%$ & $-3.13 \%$ & $7.07 \%$ \\
\hline Average & - & $5.94 \%$ & $0.94 \%$ & $4.57 \%$ & $13.24 \%$ & $-1.34 \%$ & $3.04 \%$
\end{tabular}


397

398

399

400 